\title{
Vor und nach der Katastrophe
}

\author{
Erhard Taverna \\ Dr. med., Mitglied der Redaktion
}

Referenzen

Babylon Berlin,

Premiere am 28.9.2018,

16 Folgen à 45 Minuten Auch auf DVD.

Ralf Rothmann. Sterben Gott jenes Sommers, Suhrkamp 2016 und 2018.

erhard.taverna[at]saez.ch im Frühling und Der

Aus der zunehmenden zeitlichen Distanz wird die Vergangenheit neu erzählt. Die deutsche TV-Staffel Babylon Berlin ist die teuerste Serie aus der Kooperation von ARD mit dem Privatsender Sky. Drei Regisseure und ein Starensemble spielen die letzten Jahre der Weimarer Republik. Genauer das Jahr 1929, das Jahr der Weltwirtschaftskrise, das Jahr von Döblins Berlin Alexanderplatz.

Eine unbedingt sehenswerte Filmproduktion über ein Grossexperiment der Moderne, wie das Aufkommen einer demokratischen Massenkultur genannt wurde. Berlin ist die absolute Provokation, die Überforderung, die aufregendste Stadt Europas, Projektionsfläche für konservative Gegenmodelle von Heidegger bis Benn, von Provinzlern und ewig gestrigen Kriegsgurgeln. Partyzone, Popkultur, Massenarmut, Endzeitstimmung, Anarchie. Ein Gefühl von Paranoia und die zunehmende Brutalität der Strasse dominieren die fiktionale Handlung. Ein Jahr später bricht der Sozialstaat zusammen. Noch einmal drei Jahre und Hitler übernimmt die Macht. Die spannenden Handlungsstränge kulminieren immer wieder im Tanz am Rande des Abgrunds. Selbstsichere Frauen, Schwule und Lesben, moderne Mode, Raves, Dada und Bauhaus, Charleston und GoGo-Tänzerinnen à la Josephine Baker bestimmen die Nächte im Vergnügungstempel Moka Efti. Rauschhafte Bilder, wo eine androgyne Schönheit die Menge in Ekstase singt: «Ozean der Zeit [...] zu Staub zu Asche, doch noch nicht jetzt.» Eine von vielen gelungenen Figuren, in der Nosferatu mit einem Popstar verschmilzt. Wir Nachgeborenen wissen, wie es herausgekommen ist. Ängste, dass Demokratie und Wohlstand untergehen

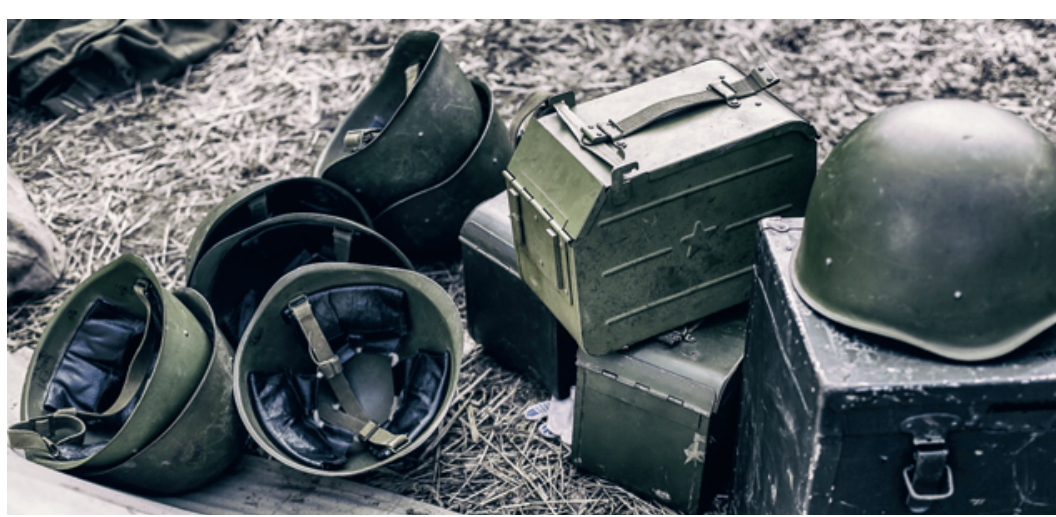

könnten, entdecken in den Weimarer Jahren eine Warnung für die Gegenwart. Wer die Literatur weniger kennt, weder Kästner, Fallada, Brecht noch viele andere gelesen hat, findet eine gute Gelegenheit, sich mit den Jahren vor der Katastrophe der Nazizeit auseinanderzusetzen. Darüber nachzudenken, wo wir heute wären, wenn es ganz anders verlaufen wäre.

Die Schuld der Väter verfolge ich bis in die dritte und vierte Generation, so spricht der biblische Jahwe. Die Väter haben saure Trauben gegessen, aber den Kindern sind die Zähne davon stumpf geworden, zitiert Ralf Rothmann den Propheten Ezechiel zu Beginn seines Romans Sterben im Frühling. Das Buch handelt von zwei Freunden, die beide, noch kaum erwachsen, kurz vor Kriegsende zur SS zwangsrekrutiert werden. Unschuldig schuldig. Der eine wird als Deserteur hingerichtet, der andere heiratet nach der Rückkehr seine Jugendliebe, bleibt aber bis an sein Lebensende traumatisiert. Stellvertretend für die erste Generation bleibt er stumm. An dem, was die Väter und Mütter verschweigen, arbeiten sich die Söhne und Enkel ab. Hier ist es der Sohn Rothmann, der das Schreiben übernimmt, ein grossartiger Erzähler, der die letzten Kriegsmonate aus der Sicht des jungen Melkers alptraumhaft verdichtet. Er tut es noch einmal im folgenden Roman Der Gott jenes Sommers, in dem eine Jugendliche an der sogenannten Heimatfront den Zusammenbruch erlebt. Nach Borchert und Böll die nächste Generation, die immer die gleichen Geschichten aus einem wieder anderen Blickwinkel erzählt. Es wird nicht Schuld gegen Schuld aufgerechnet. Geschundene Menschen gleichen sich. Das ist vielleicht die eine Botschaft eines Schriftstellers, der zu den besten gehört, die der deutsche Sprachraum aktuell zu bieten hat. Wer will, findet in jeder Suppe ein Haar. Wer den Autor in die Nähe von Konsalik rückt, weil da ein neuer Landserroman entstanden sei, übersieht das Wesentliche der Botschaft. Kein Heldentum, keine Weisswäsche, keine Mythisierung. Auffallend viele Filme und Bücher beschäftigen sich aktuell mit den Krisenzeiten, die Europa tief geprägt haben. Vielleicht ist es wieder an der Zeit, aus grösserer Distanz die Jahre vor und nach der Katastrophe zu betrachten. Eine Chance, mehr nicht.

Bildnachweis

(c) Fotomaler | Dreamstime (Symbolbild)

(Rekonstruktion mit Gegenständen aus dem Zweiten Weltkrieg) 